\title{
O DE SEMPRE E O DE NUNCA: GELO E NEVE EM CIEN AÑOS DE SOLEDAD, DE Gabriel García MÁrqueZ, E “The DEAD”, DE JAMES Joyce
}

\author{
The usual and the unusual: ice and snow in Gabriel \\ García Márquez's Cien años de soledad and James \\ Joyce's "The dead"
}

\author{
Victoria Saramago*
}

\section{I - O FAMILIAR E o EXótico}

Publicado em 1914, o último conto de Dubliners, "The Dead", é frequentemente considerado uma das obras primas de James Joyce, sobretudo por seu famoso final, em que o protagonista Gabriel Conroy fita, de dentro de seu quarto, a neve caindo sobre Dublin à noite. A cena se dá após um perturbador diálogo com sua esposa Gretta acerca de um amor adolescente desta, Michael Furey, morto ainda na juventude. Gabriel se volta então para a janela do hotel onde o casal se hospedara para uma festa de família, e contempla os flocos de neve caindo noite adentro, debilmente iluminados pelos lampiões.

O que sobressai aqui é a imagem de uma neve onipresente. Há neve por toda a Irlanda, como previram os jornais, há neve por suas planícies, montanhas, rios, pelas ruas e os portões de Dublin e as igrejas. A neve cobre até mesmo o túmulo de Michael Furey em Galway, como cobre o teto que abriga Gabriel. A neve cai sobre os vivos tanto quanto sobre os mortos, sem distinções, e o espírito de Gabriel acompanha este movimento na derradeira frase do livro: "His soul swooned slowly as he heard the snow falling faintly through the universe and faintly falling, like the descent of their last end, upon all the living and the dead." ${ }^{1}$ (JOYCE, 2001, p. 160)

\footnotetext{
Universidade do Estado do Rio de Janeiro

"Sua alma desmaiava lentamente, enquanto ele ouvia a neve cair suave através do universo, cair brandamente - como se lhes descesse a hora final - sobre todos os vivos e todos os mortos." (Trad. Hamilton Trevisan)
} 
Segundo Richard Ellman (1989), tal passagem alude provavelmente a um símile presente no canto XII da Ilíada, no qual as grossas flechas dos gregos e dos troianos são descritas como flocos de neve caindo generalizadamente sobre todo o território. Ellman sustenta, porém, que, diferente do que ocorre em Homero, a neve em "The Dead" representa um senso de ligação entre os personagens, "um senso de que ninguém é sozinho" (ELLMAN, 1989, p. 317). Pois inerente ao tom lírico da conclusão de "The Dead" é a percepção da neve como um elemento universalizante, capaz de abarcar todos os seres humanos, estejam eles vivos ou mortos, como um imenso manto homogeneizador a dissolver suas diferenças. Com efeito, a neve que Gabriel vê cair em sua janela se estende a toda a Irlanda, através das notícias dos jornais, e em seguida a todo o universo, dessa vez por causa de um sentimento indefinido de Gabriel para com a humanidade. As possibilidades interpretativas de tal trecho são inúmeras, como veremos adiante, mas permanece uma constante, em grande parte dos estudos dedicados a esta obra, a ideia de que a neve constitui um elemento unificador e diluidor de identidades individuais, inclusive pelo tom ao mesmo tempo conclusivo e melancólico que marca a passagem.

Deixando por ora de lado os parágrafos finais de Dubliners, leiamos a abertura de Cien años de soledad, de Gabriel García Márquez, cuja primeira publicação data de 1967: "Muchos años después, frente al pelotón de fusilamiento, el coronel Aureliano Buendía había de recordar aquella tarde remota en que su padre lo llevó a conocer el hielo." (MÁRQUEZ, 2007, p. 9). As primeiras palavras do romance, "muchos años después", referem-se especificamente à tarde em que José Arcadio Buendía levou seu filho Aureliano à tenda dos ciganos para conhecer o gelo, elemento tão estranho ao tórrido clima tropical de Macondo, que o patriarca dos Buendía não encontrou outra maneira de defini-lo senão como "el gran invento de nuestro tiempo"2 (MÁRQUEZ, 2007, p. 28).

Narrado com vagar ao final do primeiro capítulo, o episódio assinala o início de um processo que se estenderia e se aprofundaria ao longo de toda a obra, exercendo influência decisiva sobre o destino dos Buendía e de Macondo: a chegada ou invasão de objetos, organizações e hábitos estrangeiros, sobretudo os pertencentes à cultura europeia, bem como sua necessária adaptação à realidade macondiana, a despeito de seu aspecto peculiar ou mesmo sobrenatural.

Nesse contexto, os ciganos desempenham um papel fundamental, como propiciadores dos primeiros contatos de Macondo com o exterior. Se no início tal intercâmbio se dava através do grupo de Melquíades, a posterior chegada de outros grupos sinaliza um aprofundamento, ainda que

2 "A grande invenção de nosso tempo." (Tradução minha) 
rudimentar, desse duradouro processo. Trazido pelos novos bandos itinerantes, o gelo se encontra no auge desses primeiros contatos, instalandose definitivamente como uma das mais importantes memórias do coronel Aureliano, e arrancando a já mencionada observação de José Arcadio Buendía. Um tão grande "invento", afinal, prenunciava um futuro próspero em descobertas surpreendentes e infindáveis possibilidades. Era, sem dúvida, o início de um novo ciclo.

Comparando agora o conto "The Dead" com Cien años de soledad, fica evidente a diferença entre os tratamentos dispensados a um mesmo elemento - a neve, o gelo: conclusivo, melancólico e universalizante, num caso; noutro, introdutório, vibrante e exótico. O primeiro objetivo do presente trabalho é investigar tal contraste, a partir de discussões acerca das noções de local, universal, cotidiano e exótico propostas por análises das duas obras, sobretudo no âmbito dos estudos pós-coloniais. Pretende-se, em seguida, evidenciar as possibilidades narrativas proporcionadas pelos diversos aproveitamentos da neve e do gelo, bem como relacioná-las ao tratamento das temporalidades proposto em cada caso.

\section{II - O Gelo em Cien AÑos DE SoledAD}

No livro de entrevistas El olor de la guayaba, García Márquez aponta uma imagem visual específica como o ponto de partida para a composição de Cien años de soledad: "un viejo que lleva a un niño a conocer el hielo exhibido como curiosidad de circo"3 (MENDOZA, 2005, p. 44). Com efeito, o gelo permanece um elemento recorrente em toda a obra, seja no primeiro encontro de José Arcadio Buendía e Aureliano com "el gran invento de nuestro tiempo" na tenda dos ciganos, seja nas frequentes recordações deste último, seja nas fábricas de gelo e de sorvetes abertas muitos anos depois por dois de seus inúmeros filhos, os Aurelianos Triste e Centeno. Jonathan Tittler (1990) classifica o gelo como uma das três imagens fundamentais da obra, junto à árvore e à mariposa. Segundo Tittler,

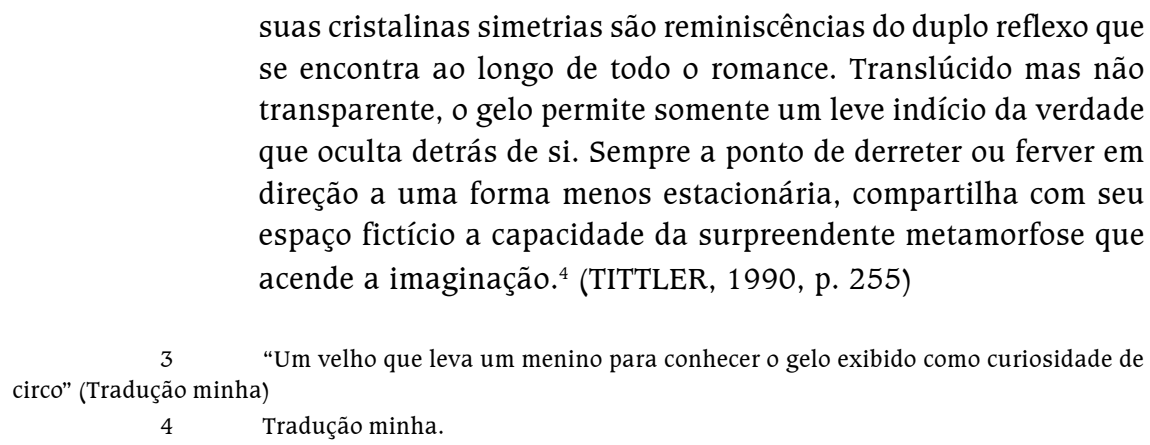
se encontra ao longo de todo o romance. Translúcido mas não transparente, o gelo permite somente um leve indício da verdade que oculta detrás de si. Sempre a ponto de derreter ou ferver em direção a uma forma menos estacionária, compartilha com seu espaço fictício a capacidade da surpreendente metamorfose que acende a imaginação. ${ }^{4}$ (TITTLER, 1990, p. 255) 
Considerando essa natureza do gelo no contexto dado, "translúcida mas não transparente" e sempre a ponto de se desfazer para passar a um outro estado, seria interessante compará-la às características mais proeminentes do realismo maravilhoso, do qual Cien años é com certeza um dos mais emblemáticos representantes. Lembremos, por exemplo, o estudo de Irlemar Chiampi (1980) sobre o gênero, segundo o qual este "contesta a disjunção dos elementos contraditórios ou a irredutibilidade da oposição entre o real e o irreal" (CHIAMPI, 1980, p. 61). Ou levemos em conta a afirmação de Ato Quayson (2006) de que "confundindo qualquer senso simples e claro de hierarquias espaciais, éticas ou motivacionais entre $o$ real e o fantástico, o realismo mágico gera uma escrupulosa equivalência entre os dois domínios"5 (QUAYSON, 2006, p. 728), de modo que haveria uma espécie de interação entre ambos.

Abrem-se aqui caminhos bastante produtivos para pensar tal interação entre o real e o fantástico. Em princípio, parece-me possível sustentar que a imagem do gelo está próxima, nesse caso, ao discurso do realismo maravilhoso: o discurso não-estacionário e oscilante, que não é opaco, mas não se presta a um exame calcado no pensamento racional tal como o postulado pela racionalidade iluminista, uma vez que real e fantástico se encontram em um estado de constante negociação.

Pensemos também a curiosa escolha de um elemento tão estranho ao tórrido clima da selva colombiana para representar uma das imagens centrais da obra ou mesmo seu ponto de partida. Afinal, a apropriação de um elemento exótico e sua consequente realocação no contexto macondiano, bem como os diversos modos pelos quais os Buendía definem o gelo e os usos distintos que dele fazem, todos esses fatores sugerem que seria impossível conceber Macondo sem levar em conta os contatos culturais decorrentes da frequente chegada e assimilação de elementos estrangeiros. É possível concluir, então, que os processos de hibridação e negociação cultural se encontram nas bases da identidade de Macondo. Como sustenta Jean-Marc Moura (1999) a propósito das literaturas ditas póscoloniais, trata-se

de estudar a escritura de uma identidade em formação fundada sobre uma negociação cultural constante, [na qual] o reconhecimento de um eu plural, objeto de uma negociação permanente entre a origem e a cultura dominante e o exame de sua expressão literária constituiriam uma nova direção dos estudos pós-coloniais ${ }^{6}$ (MOURA, 1999, p. 155).

5 Tradução minha.

6 Tradução minha. 
Prosseguindo no pensamento de Moura, o realismo maravilhoso seria especialmente interessante na construção dessa identidade, uma vez que "o recurso ao sobrenatural [...] pode ter uma função mais particularizante: ele retira a obra do espaço hermenêutico ocidental para sugerir uma particularidade local intraduzível." (MOURA, 1999, p. 146) No caso de Macondo e dos contatos de seus habitantes com o gelo, essa particularidade estaria certamente nas formas através das quais o gelo é percebido e manipulado, sobretudo no início de Cien años, e que fogem ao que entendemos por "espaço hermenêutico ocidental". Vejamos algumas delas.

Em primeiro lugar, o gelo é classificado por José Arcadio Buendía como uma invenção entre outras, ao lado do astrolábio, da lupa, do ímã ou do daguerreótipo. Uma paisagem nevada como a descrita no parágrafo final de "The Dead", por exemplo, seria provavelmente inimaginável aos habitantes de Macondo. Aliás, a própria associação entre neve/gelo e paisagem soaria tão irreal quanto uma paisagem composta de astrolábios. Conclui-se daí que o gelo deixa o domínio do natural e passa ao do artificial. Foge, portanto, a uma das mais básicas distinções colocadas por Aristóteles, a de que a natureza nasce, se origina e existe por si mesma, tendo em si o princípio de seu próprio movimento, ao passo que o artifício é aquilo que é criado pelo homem e depende de sua ação para existir. Percebemos que, se o trecho de Joyce em questão se encaixa perfeitamente nessa concepção, o romance de García Márquez a põe sutilmente em discussão.

Em segundo lugar, e justamente por pertencer ao âmbito do artificial e do tecnológico, o gelo é encarado ao longo de toda a obra por um viés altamente utilitarista. No início explorado pelos ciganos como uma curiosidade a ser exibida nos circos, depois transformado em matéria-prima das fábricas de gelo e de sorvete dos Aurelianos Triste e Centeno, e por fim usado para preencher os caixotes de comida importados da Europa por Amaranta Úrsula, o gelo recebe o tratamento de um instrumento ou um material entre outros, a serviço de uma finalidade que está para além dele.

Finalmente, é interessante notar que, apesar de não familiarizados com o gelo, os personagens de Cien años têm seus sentimentos frequentemente descritos através de metáforas que a ele aludem, como "cuando el hielo del corazón la despertaba em la cama solitaria"7 (MOURA, 1999, p. 253) ou

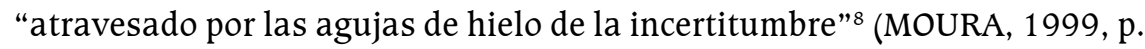
437). Com isso, o gelo, mesmo permanecendo denotativamente um elemento raro e exótico, inspira uma certa familiaridade no nível conotativo. A meu 
ver, há aqui uma evidência de que, apesar de solapar as bases da racionalidade nos moldes ocidentais, a obra ainda assim assume sua vinculação ao modelo e às formas de percepção próprias do ocidente. Mais do que um caso de dependência cultural, esse detalhe reforça, na minha opinião, o caráter híbrido e plural da identidade macondiana.

\section{III - A NeVE EM “The DEAD”}

Levando em conta essas observações, voltemos agora a "The Dead", e consideremos em que medida a comparação com o romance de García Márquez pode lançar novas luzes sobre o conto de Joyce. Afinal, como sustenta Moura, "sem dúvida, aqui tem início um olhar novo sobre os países europeus, apoiado nessa outra face de nossa modernidade onde são produzidos signos, símbolos, temporalidades e práticas culturais diferentes, e onde começam a se renegociar as formas de vida comunitária." (MOURA, 1999, p. 155)

Antes de mais nada, é necessário observar que, diferente do que se deu com a crítica de Cien años, as interpretações de "The Dead" realizadas ao longo do século XX e início do XXI são tão profusas e contraditórias, que o seu exame revela-se um problema de especial delicadeza. Afinal, se o romance de García Márquez, publicado em 1967, foi largamente intepretado à luz de teorias pós-estruturalistas e pós-modernas, assumindo grande relevo nos estudos pós-coloniais dedicados à Améria Latina, Dubliners, cuja primeira publicação data de 1914 , foi objeto de estudo das mais variadas correntes teóricas. Dessa forma, a fortuna crítica da obra é composta tanto de leituras formalistas, que em geral interpretam o último parágrafo de "The Dead" por um viés essencialista, quanto por linhas mais próximas aos estudos culturais e pós-coloniais, cujas leituras ressaltam o caráter localizado do simbolismo da neve no conto em questão.

Nos anos 40 e 50 do século passado, por exemplo, ensaios clássicos como os de Allen Tate e Kenneth Burke se pautaram por essa visão mais essencialista. $O$ primeiro apresenta a neve como um símbolo fundamental da epifania de Gabriel, de escape de seu ego individual em direção a um sentimento de humanidade. Já o segundo coloca o tópico da neve como "uma imagem mítica, no mundo das condições, representando a transcedência sobre o condicionado"10 (BURKE, 1996, p. 401). Richard Ellman, por sua vez, analisa a obra tendo por pano de fundo a biografia de Joyce, mas não se afasta muito das leituras de Tate e Burke: "Debaixo desse dossel [da neve] todos os seres humanos, não importa seus graus de intensidade,

9 Tradução minha. 
unem-se. A reciprocidade é que todos os homens sentem e perdem o sentimento, todos interagem." (ELLMAN, 1982, p. 318). Ellman observa ainda que, constituindo uma "melancólica aceitação de tudo o que a vida e a morte oferecem, 'Os mortos' é uma chave na obra de Joyce." (ELLMAN, 1982, p. 318)

Se por um lado a importância de "The Dead" no conjunto da obra de Joyce segue incontestada, essa "melancólica aceitação" que une todos os seres humanos, seja os vivos seja os mortos, vem sendo, nas últimas décadas, objeto de veementes questionamentos e reformulações. É o caso do artigo “"The Dead' and the Generosity of the Word", no qual Vincent Pecora, considerando a linguagem de Ellman neutra e, por conseguinte, acrítica, propõe uma leitura do fim do conto baseada em dois aspectos-chave da cultura irlandesa: a hospitalidade e a retórica do autossacrifício, cuja origem remonta ao calvário de Cristo e à força do catolicismo na Irlanda. Trata-se, para Pecora, de um clichê ideológico investigado por Joyce ao longo de todo o conto, e explicitado nas "lágrimas generosas" dispensadas por Gabriel, no penúltimo parágrafo, a Michael Furey, o falecido amor adolescente de sua esposa Gretta. Dessa maneira, segundo Pecora,

\begin{abstract}
a forma que esta hospitalidade - este auto-sacrifício institucionalizado - toma em Gabriel é sem dúvida a única virtude que ele afinal retém, o único código intencional ao qual se prende quando tudo mais falhou - a sua "generosidade". Assim, a noção de generosidade como auto-sacrifício, aparecendo em toda a história, precisa ser examinada agora no contexto de uma tradição já formulada para o uso, uma máscara cultura tão inefável e significativamente transparente que Gabriel pode esconder-se por trás dela como se não houvesse máscara alguma (PECORA, 1986, p. 238).
\end{abstract}

De fato, o movimento em direção a investigações calcadas em aspectos culturais tomou fôlego suficiente para que, em meados dos anos 1990, autores como Enda Duffy, Declan Kiberd, David Lloyd, Vincent Cheng ou Emer Nolan classificassem James Joyce como um autor pós-colonial, ou mesmo, segundo Duffy, como o inaugurador de um modernismo póscolonial. ${ }^{11}$ Nessa perspectiva, importantes características da prosa joyceana, como o experimentalismo formal destoante do realismo vitoriano, a multiplicidade de vozes e pontos de vista e até mesmo o diálogo com tradições orais irlandesas seriam componentes de um discurso anti-imperialista, independente, pluralista e democrático.

11 Dados retirados de MOORE-GILBERT, Bart. Postcolonial Modernism. In: BRADSHAW, David; DETTMAR, Kevin J. H. A companion to modernist literature. Blackwell Publishing, 2006. p. 551557. 
Por fim, concordando apenas parcialmente com a alcunha de "póscolonial" dada a Joyce, os organizadores de Semicolonial Joyce (2000), Marjorie Howes e Derek Attridge, justificam da seguinte maneira suas reservas à aplicação do termo ao escritor: suas obras,

ao lidarem com questões de nacionalismo e imperialismo, evidenciam uma complexa e ambivalente gama de atitudes, não reduzível a um simples anti-colonialismo, mas muito distante de alguma aprovação das organizações e métodos coloniais com os quais a Irlanda sofreu uma longa história de opressão, e continuou a sofrer durante sua vida [de Joyce] (HOWES; ATTRIDGE, 2000, p. 3).

Diante dessas considerações, pensemos duas técnicas muito utilizadas por Joyce em Dubliners, apontadas por Seamus Deane no primeiro ensaio de Semicolonial Joyce, "Dead ends". A primeira é a repetição, resultante de uma "gramática monótona" que perpassa as histórias, acentuando "o senso de repetitividade infantil que é a perpétua característica da condição de Dublin" (DEANE, 2000, p. 21). Sua origem, segundo Deane, encontra-se num misto de servidão e "identidade de segunda mão" decorrentes do controle britânico sobre a Irlanda ligado à sua entrada um tanto enviesada na modernidade, o que terminaria por criar uma duplicidade do sistema capitalista nesse local, gerando uma espécie de paralisia em seus habitantes. Já a segunda técnica, a transformação de um elemento sólido em algo espectral, é exposta da seguinte maneira por Deane:

o que vemos aqui é o método joyceano de contrapor aquilo que é inegavelmente real [...] a algo que é inegavelmente falso e então, em vez de ratificar o "real", mostrar que este pode ser engolido pelo mundo ilusório, rendido a ele, por aqueles que são, como os dublinenses, ávidos por ilusão, gratos por serem oprimidos por algo "mágico" que de alguma forma dissolva ou pareça dissolver a esqualidez do factual (DEANE, 2000, p. 23).

Apesar do adjetivo "mágico" utilizado por Deane, acredito não ser o caso de considerar que Joyce se aproximasse do realismo maravilhoso. Antes, parece-me que essa técnica está mais próxima do que Marjorie Howes, em outro ensaio da mesma obra, classificou como uma tensão entre o movimento geográfico material e o metafórico, ou "as complexas materialidades das escalas espaciais versus sua apropriação simbólica e metaforização" (HOWES, 2000, p. 65). 
Tendo em mente tais procedimentos narrativos, voltemos ao último parágrafo do conto. Decerto, os dados colocados são prosaicos: a neve cobre toda a Irlanda, como anunciaram os jornais, e Gabriel tem uma comprovação parcial dessa notícia ao assistir aos flocos de neve caindo em frente a sua janela. Entretanto, a constante reiteração de que a neve cai por toda parte, bem como a exaustiva repetição de termos como "falling", "faintly" ou "softly", ${ }^{12}$ sempre relacionados ao movimento da neve, promovem essa passagem do factual ao etéreo ou essa metaforização do geográfico. Assim, o cair da neve termina por ganhar um acento lírico, da mesma forma que, estendendo-se ao Bog of Allen, à planície central, à região oeste e a toda a Irlanda, abarca enfim o próprio universo. É possível notar, portanto, que da técnica da repetição, aliada à da apropriação simbólica, resulta a formação do que se poderia classificar como uma nova camada interpretativa, metafórica e liricizada, que se sobrepõe à da realidade prosaica e lhe dá dimensões mais amplas. Sabemos que "the newspapers were right: snow was general all over Ireland" ${ }^{13}$ (JOYCE, 2001, p. 160), mas a essa frase se acrescenta outra que expande seu alcance e confere ao texto novas tonalidades: "the snow [was] falling faintly through the universe and faintly falling, like the descent of their last end, upon all the living and the dead." ${ }^{14}$ (JOYCE, 2001, p. 160)

Levemos em conta também o ponto de vista de Gabriel. Sabemos que a neve é por ele percebida através do filtro de suas próprias emoções no momento, decorrentes da confissão de Gretta sobre Michael Furey e de suas experiências ao longo da noite e do jantar em família. Se consideramos que tais emoções têm uma dimensão transcendental, como defendem Tate e Burke, ou se preferimos tomá-las como reflexos de aspectos da cultura irlandesa, como colocam Pecora e os teóricos dos estudos pós-coloniais, em qualquer dos casos permanece a possibilidade de pensar essa sobreposição de uma outra camada ao do que entendemos por real ou prosaico, esteja sua origem na cultura irlandesa, esteja ela na natureza humana. É o que Deane afirma a respeito da técnica da repetição no final de "The Dead": "não se trata de um sistema que pertença à 'História' ou à 'Humanidade'. Pertence apenas à escrita." (DEANE, 2000, p. 35) Falamos, portanto, de um procedimento de composição literária, a partir do qual a intensificação e repetição de um dado prosaico geram um nível não prosaico, mas metafórico e liricizado.

\footnotetext{
"Caindo", "debilmente" e "suavemente".

"os jornais estavam certos: a neve cobria toda a Irlanda" (Trad. Hamilton Trevisan)

"a neve [a] cair suave através do universo, cair brandamente - como se lhes descesse a hora final - sobre todos os vivos e todos os mortos." (Trad. Hamilton Trevisan)
} 


\section{IV - ESCRITAS DE RESISTÊNCIA}

Vimos que o realismo maravilhoso de García Márquez se forma no contraste entre o "espaço hermenêutico ocidental" e um outro que lhe é estranho, ou seja, no choque e negociação entre o que, dentro da racionalidade ocidental, entendemos por real e sobrenatural. Nesse caso, o gelo, como elemento radicalmente estranho à visão de mundo macondiana, representa um inevitável desencadeador de tal choque, e com isso evidencia a existência de dois níveis hermenêuticos distintos.

No final de "The Dead", porém, não cabe falar em dois níveis hermenêuticos: há apenas um, o ocidental. A neve cobre a Irlanda como poderia cobrir a Inglaterra, ou qualquer outro país europeu. Nesse caso, a lógica do dominado não se opõe inicialmente à do dominador, pois não há, em princípio, duas visões de mundo em disputa. O que há é um único nível que, através de procedimentos estilísticos como a repetição e a intensificação, desdobra-se e ganha tonalidades etéreas e espectrais, para usar os termos de Deane, ou simbólicas e metafóricas, para usar os de Howes.

o resultado, nos dois casos, não deixa de ser uma forma de resistência. Afinal, tanto García Márquez quanto Joyce fazem uso de um mesmo elemento - o gelo/neve - para, através da exploração de seu caráter radicalmente exótico ou radicalmente cotidiano, subverter ou questionar o discurso do colonizador. Em ambas as situações, é criada uma segunda camada significativa que lhe dá novas dimensões. A maior diferença, no que tange a composição literária de cada uma, é provavelmente a de que Joyce se vale sobretudo de recursos estilísticos, ao passo que García Márquez se detém no plano da construção do enredo. Com tais constatações, acredito ser possível formular algumas hipóteses.

Em primeiro lugar, é necessário ressaltar que, por esse viés, possibilidades interpretativas bastante frutíferas podem ser desenvolvidas no âmbito dos estudos pós-coloniais, como defendem os já citados teóricos a respeito de Joyce ou, por exemplo, Stephen Slemon (1995) a respeito do realismo maravilhoso, em seu ensaio "Magic realism as postcolonial discourse". Talvez, na verdade, fosse mais adequado falar, no caso de Joyce, em uma condição semicolonial, como sustentam Attridge e Howes, dada a situação especial da Irlanda entre as sociedades pós-coloniais.

Entretanto, independentemente do rótulo a ser adotado, o que fica evidente é a diversidade e a complexidade das escritas que põem em questão os discursos dos dominadores, e que não podem ser ignoradas por quaisquer de suas leituras críticas. Como coloca Zulma Palermo (2003) no ensaio "Comparatismo contrastivo y hermenéuticas pluritópicas: variaciones latinoamericanas", 
assim como o estudo contrastivo oferece uma forma de aproximação pertinente ao objeto de estudo (sujeito heterogêneo) por nele haver uma coexistência de vários sistemas e de vários processos com diferentes graus e níveis de contato, a interpretação dos sistemas assim descritos requer não mais uma hermenêutica monotópica segundo a qual a compreensão é uma e mesma, sem distinguir as diferenças entre os sujeitos culturais - mas de uma hermenêutica pluritópica, que parta da pluralidade de tais sujeitos buscando compreendê-los precisamente em suas diferenças ${ }^{15}$ (PALERMO, 2003, p. 324).

Apesar de concentrar-se nas diferentes vozes presentes no interior da América Latina, acredito que Palermo expõe o problema com precisão, e que o termo "hermenêutica pluritópica", emprestado de Walter Mignolo, sintetiza com eficiência o modo pelo qual devem ser abordadas as diferenças aqui analisadas entre García Márquez e Joyce, bem como tantas outras.

Em segundo lugar, cabe investigar também em que medida essas diferenças culturais podem trazer novos desdobramentos ao estudo do gênero romance e da prosa de ficção em geral. Pois tanto a capacidade formal do romance de assimilar novos discursos e técnicas quanto sua natureza maleável e sem regras rígidas abrem o gênero à incorporação de discursos e visões de mundo distintos do modelo europeu. É o que coloca Cornejo Polar (2000) em "Problemas e perspectivas da crítica literária latinoamericana" acerca do romance latino-americano: nele são introduzidos elementos não romanescos das culturas orais e locais, criando uma forma heterogênea que responde à própria condição da sociedade. Da mesma forma, essa introdução, à medida que dá espaço a essas outras vozes, influencia a própria natureza do gênero, em suas possibilidades narrativas e textuais. Ainda no caso latino-americano, tais transformações foram magistralmente analisadas, por exemplo, por Ángel Rama (2001), sob o conceito da "transculturação narrativa", isto é, uma coexistência dos discursos europeu e o nativo, de modo a formar um terceiro discurso que os sintetiza, mas ao mesmo tempo não os anula. Entre os mais nítidos exemplos de transculturação narrativa, segundo Rama, está Cien años de soledad. Já no caso de Joyce, ainda que Dubliners não esteja entre suas obras mais experimentais, seria absolutamente ocioso expor a influência decisiva da prosa joyceana sobre toda a narrativa a ela posterior. Minha opinião, enfim, é a de que há aqui um duplo movimento: se por um lado a maleabilidade do romance incentiva a agregação de outros discursos e práticas culturais, por outro, essa agregação modifica os parâmetros que definem o gênero.

$$
15 \text { Tradução minha. }
$$


Aproveitando esse último movimento, voltemos à comparação entre a neve e o gelo em Cien años e "The Dead". Neste ponto, é de se perguntar sobre como tão distintas abordagens, condicionadas por suas diferenças culturais, se encaixam no plano da narrativa. Em outras palavras, qual seria o rendimento, para o enredo, de cada uma das utilizações da neve e do gelo. Analisemos, a seguir, alguns aspectos da questão.

\section{V - DA NARRATIVA E DA TEMPORALIDADE}

No caso de García Márquez, como fora colocado no início deste trabalho, gelo significa futuro, possibilidade e contato com o novo. Em vez de uma visão retrospectiva e totalizante, como veremos em Joyce, ele lança luz à diferença e ao porvir, sendo portanto marcadamente prospectivo. Não à toa, aparece principalmente quando uma das fases da saga macondiana está prestes a se encerrar para dar lugar a outra.

Por "fases da saga macondiana" entendo a subdivisão temporal do enredo muito frequente nos estudos críticos sobre a obra. Em geral, as delimitações variam bastante, sendo cada fase marcada ou por uma temporalidade diversa, ou pelo predomínio de um determinado sistema político-econômico. Claudio Guillén (2007), no artigo "Algunas literariedades de Cien años de soledad", adota a distinção entre o tempo mítico da época da fundação da cidade e o tempo histórico, iniciado mais ou menos nas guerras civis. o primeiro momento, ao qual pertence o episódio em que José Arcadio Buendía e Aureliano veem o gelo na tenda dos ciganos, está dominado, entre outras coisas, pelos sentimentos arquetípicos e o desejo de conhecimento. "A princípio tudo ocorre pela primeira vez. o ímã, o gelo, a lupa, tudo é pioneiro, tudo é fundacional. Tudo é inusitado porque ainda não há usos, tudo é insólito porque não há costumes." ${ }^{16}$ (GUILLÉN, 2007, p. CXIII)

Não é de se estranhar, dessa forma, que o gelo figure no início do livro como o dado novo a ser assimilado. Aparece já na primeira frase de abertura, num movimento proléptico, e fecha o primeiro capítulo, no qual o exíguo contato com outras culturas ainda não é forte o suficiente para abalar o caráter mítico destes tempos inaugurais. ${ }^{17}$ Funciona, assim, como precursor dos contatos com o estrangeiro que permearão toda a obra, além de assinalar ao leitor que este se encontra em um sistema interpretativo distinto do ocidental. Como sustenta Franco Moretti (1996), "nesta primeira fase, de fato, a interferência enriquece a vida de Macondo: faz dela mais variada, mais aberta. É o momento no qual a palavra-chave do modernismo -

16 Tradução minha.

17 Segundo Franco Moretti, "o encontro com o sistema-mundo produz aberrações, mas não consequências irreversíveis.” (MORETTI, 1996, p. 244) Tradução minha. 
possibilidade - invade cada página da história."18 (MORETTI, 1996, p. 244) No entanto, como observa Guillén ao retomar Genette, devemos levar em conta

o fato de que a primeira vez, na medida em que se experimenta intensamente seu valor inaugural, é sempre ao mesmo tempo uma última vez, ao menos porque é para sempre a última das primeiras vezes, e que, depois dela, inevitavelmente, começa o reino da repetição e do costume ${ }^{19}$ (GUILLÉN, 2007, p. CXIII).

Dentro, então, do tempo histórico, da repetição e do costume, o gelo continua invocado como possibilidade, mas seu "valor inaugural" já se esvaiu por completo: é agora a vez das fábricas de gelo e sorvete dos Aurelianos Triste e Centeno, e das caixas de comida preenchidas de gelo importadas da Europa por Amaranta Úrsula. Em vão o coronel Aureliano tenta recuperar em sua memória o episódio da tenda dos ciganos, e sua nostalgia dessa época primeira é, com efeito, uma das causas centrais de sua crescente amargura. Reitera-se assim o valor utilitarista do gelo, bem como sua natureza mais próxima de um artefato do que de um elemento natural, porém já dentro de uma lógica histórica, ou seja, sem o fascínio despertado nos tempos míticos.

Já no caso de "The Dead", como já fora mencionado, a neve aparece na narrativa como um dado retrospectivo e totalizante. Constituindo uma espécie de ponto final do livro, concentra o que há de conclusivo não apenas em "The Dead", mas em todos os contos de Dubliners. Pois certamente seria possível interpretar a neve que cai sobre todos os vivos e os mortos como um elemento unificador de todos os personagens apresentados no livro, como aquilo que afinal têm em comum e que aponta para um mesmo destino: o território dos mortos, com os quais inclusive já compartilham o cair da neve.

Aqui é interessante notar que se poderia falar também de um tempo mítico e absoluto, semelhante ao que permeia os tempos fundacionais de Macondo. Como sustenta C.C. Loomis,

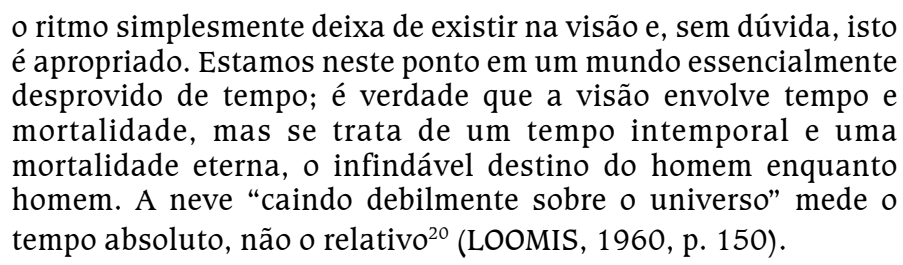
é apropriado. Estamos neste ponto em um mundo essencialmente desprovido de tempo; é verdade que a visão envolve tempo e mortalidade, mas se trata de um tempo intemporal e uma mortalidade eterna, o infindável destino do homem enquanto homem. A neve "caindo debilmente sobre o universo" mede o tempo absoluto, não o relativo ${ }^{20}$ (LOOMIS, 1960, p. 150).

$\begin{array}{ll}18 & \text { Tradução minha. } \\ 19 & \text { Tradução minha. } \\ 20 & \text { Tradução minha. }\end{array}$


Como podemos perceber, o artigo do qual esse trecho foi retirado, "Structure and sympathy in Joyce's 'The Dead'”, data de 1960. Encontra-se, portanto, mais próximo às interpretações essencialistas de Tate ou Burke. Emer Nolan (1995), por exemplo, na abordagem pós-colonial desenvolvida em James Joyce and Nationalism, relaciona a coexistência deste tempo absoluto e intemporal e o ritmo da vida de Gabriel com o duplo tempo da nação proposto por Anderson ou Bhabha, que se explicitaria na "experiência de Gabriel, intensamente solitária, mas ainda assim compartilhada" (NOLAN, 1995, p. 36). A meu ver, independentemente deste tempo absoluto ser entendido como uma condição da humanidade ou como um aspecto da construção da nação, permanece constante, na narrativa, a ideia de que se trata de um tempo "absoluto e intemporal", ao qual se dirigem todas as histórias individuais descritas no livro de Joyce.

Como expõe Loomis em sua ótima análise, esse momento final promove a abertura de um foco que vinha se estreitando ao longo de todo o conto. De sua abertura, composta de ações variadas e difusas e da introdução de inúmeros personagens, o leitor é conduzido à cena do jantar. A partir daí o ritmo vai aumentando progressivamente e o foco se estreitando nos personagens principais, Gabriel e Gretta, até a cena do hotel, totalmente concentrada nos dois e marcada por uma forte tensão, levando, por fim, à focalização apenas em Gabriel e à sua contemplação da neve nos últimos parágrafos. ${ }^{21}$ Neste ponto, seu encontro com esse tempo absoluto dá início a um movimento inverso, de abertura de foco. Nas palavras de Loomis,

\begin{abstract}
a história inteira nos conduz a este foco estreito. Agora, como fizera com o ritmo, Joyce reverte o processo. À medida que a visão progride em direção à imagem última da neve caindo através do universo, o foco se amplia de Gretta para suas tias, para ele mesmo [Grabriel], para a Irlanda, para "o universo". [...] "The Dead" segue um padrão lógico; movemo-nos do geral ao particular, e então para um fim universal ${ }^{22}$ (LOOMIS, 1960, p. 150).
\end{abstract}

Assim, até as constantes menções à neve ao longo de "The Dead", ainda que breves, funcionariam como uma preparação para esse final. É o caso, por exemplo, de quando Gabriel remove a neve de suas galochas, ou de quando tia Kate comenta que havia trinta anos não nevava tanto. $O$ curioso é que esses momentos, em princípio triviais e pouco relevantes, trazem em si já o traço da imagem muito mais ampla e significativa que se formará ao final do texto.

\footnotetext{
21 Segmentação semelhante é feita por Kenneth Burke em "Stages of 'The Dead"”

22 Tradução minha.
} 
É possivel perceber, portanto, que o gelo e a neve parecem se mover de forma inversamente proporcional em cada uma das obras. Em García Márquez, estabelece-se como um dado de grande importância na abertura da narrativa, marcando o início da saída de um tempo mítico e inaugural e colocando inúmeras possibilidades para o futuro. Posteriormente, permanece presente ao longo da história, ainda que seu valor seja progressivamente diminuído. Em Joyce, ao contrário, a neve aparece como detalhe banal e cotidiano em meio aos personagens, ainda que as alusões a ela sejam frequentes, para no último parágrafo ganhar uma dimensão universal, que conclui a obra assinalando a entrada em um tempo mítico e absoluto. Em ambos os casos, a maneira pela qual se desenvolvem a presença do gelo e da neve tem um peso considerável no desenrolar da narrativa, na introdução de seus motivos principais e no estabelecimento de um nexo entre eles.

Seria interessante ainda retomar as características do gelo apontadas por Jonathan Tittler e compará-las com essa passagem de uma temporalidade a outra em cada obra, para a qual o gelo e a neve constituem dado fundamental. O gelo, como argumenta Tittler, "sempre a ponto de derreter ou ferver em direção a uma forma menos estacionária, compartilha com seu espaço fictício a capacidade da surpreendente metamorfose que acende a imaginação." ${ }^{23}$ (TITTLER, 1990, p. 255) Dessa forma, o caráter não estacionário do gelo e da neve, bem como sua constante capacidade de metamorfose, proporcionaria um realce especial ao caráter também fluido desse movimento essencial em cada obra, de um tempo absoluto a um histórico e vice-versa.

\section{VI - CONSIDERAÇÕES FINAIS}

Acredito, enfim, que alguns pontos aqui expostos merecem ser brevemente retomados. O primeiro é certamente a noção de permanente negociação cultural que, se já pode ser considerada subjacente a qualquer contexto cultural, ganha uma importância decisiva nas sociedades cuja identidade foi amplamente construída sob a égide do contato com o estrangeiro - as ditas sociedades pós-coloniais.

O reconhecimento dessa negociação pressupõe, em segundo lugar, o reconhecimento de que há espaços hermenêuticos distintos dos ocidentais a serem levados em conta na análise das formações de tais sociedades. Chegamos aqui à noção de hermenêutica pluritópica que, como defende Zulma Palermo, torna-se evidente sobretudo nos estudos de caráter contrastivo, como pretende o presente trabalho.

$$
23 \text { Tradução minha. }
$$


Igualmente necessário é ter em vista que as obras literárias não oferecem apenas uma visão de mundo característica do contexto em que foram criadas e/ou interpretadas: o que está em jogo também é a própria literatura, isto é, os problemas e anseios abordados por cada obra no âmbito da composição literária. No caso aqui examinado, é de se perguntar em que medida as questões colocadas pela especificidade das condições pós ou semicoloniais são respondidas e elaboradas pela prosa de ficção, em resposta simultânea às questões inerentes aos gêneros nela compreendidos, como o romance e o conto. Em outras palavras, é importante considerar os resultados, no âmbito da narrativa, da incorporação de uma determinada visão de mundo.

Ademais, como pretendo ter demonstrado, os estudos pós-coloniais vêm oferecendo contribuições significativas tanto para a fortuna crítica de García Márquez quanto para uma revisão e uma re-elaboração das abordagens mais frequentes e consagradas da obra de James Joyce. Certamente, a percepção de que ambos os autores provêm de sociedades pós ou semicoloniais vem influenciando a interpretação de seus métodos de composição textual, os temas por eles utilizados e sua organização na narrativa.

Finalmente, gostaria de atentar para o procedimento-base deste trabalho: a comparação entre a utilização de um mesmo elemento dentro de obras de autores fundamentais porém raramente contrastados, provenientes de épocas e meios distintos, com propostas igualmente diversas. A meu ver, a despeito do estranhamento possivelmente suscitado, tal contraste se mostra bastante eficiente para expor e mesmo ressaltar tanto as diferenças quanto as proximidades entre García Márquez e Joyce, revelando-se, portanto, um viés interessante para pensar, de forma integrada, as soluções narrativas encontradas pelos autores e seus contextos culturais.

\section{RESUMO}

O presente artigo propõe um estudo contrastivo do conto "The Dead", de James Joyce, e do romance Cien años de soledad, de Gabriel García Márquez, a partir da utilização de um mesmo elemento: a neve e/ou o gelo. Conclusivo, melancólico e universalizante, num caso; noutro, introdutório, vibrante e exótico; a presença do gelo revela-se um meio interessante de analisar, em cada obra, noções como local, universal, cotidiano e exótico, bem como as soluções narrativas encontradas por Joyce e Márquez, distintas porém curiosamente semelhantes. Palavras-chave: Joyce; García Márquez; narrativa. 


\begin{abstract}
This article proposes a contrastive study of James Joyce's short story “The Dead”, and Gabriel García Márquez's novel Cien años de soledad, through the utilization of a same element: snow and/or ice. In one case, it is conclusive, melancolic and universalizating. In the other, introductory, vibrant and exotic. In both, ice's presence turns out to be an interesting means to analyse, in each work, notions such as local, universal, trivial and exotic, as well as the narrative solutions developed by Joyce and Márquez, distinct but curiously similar. Keywords: Joyce; García Márquez; narrative.
\end{abstract}

\title{
REFERÊNCIAS
}

ATTRIDGE, Derek; HOWES, Marjorie. Introduction. In: ATTRIDGE, Derek; HOWES, Marjorie (Orgs.). Semicolonial Joyce. Cambridge: Cambridge University, 2000. p. 1-20.

BURKE, Kenneth. Stages in 'The Dead'. In: JOYCE, James. Dubliners. London: Penguin Books, 1996. p. 395-401.

CHIAMPI, Irlemar. O realismo maravilhoso. São Paulo: Perspectiva, 1980.

DEANE, Seamus. Dead ends: Joyce's finest moments. In: ATTRIDGE, Derek; HOWES, Marjorie (Orgs.). Semicolonial Joyce. Cambridge: Cambridge University, 2000. p. 21-36.

ELLMAN, Richard. Os fundamentos de 'Os mortos'. In: James Joyce. Tradução: Lya Luft. São Paulo: Globo, 1989. p. 307-319.

GUILLÉN, Claudio. Algunas literariedades de Cien años de soledad. In: MÁRQUEZ, Gabriel García. Cien años de soledad. Madrid: Asociación de Academias de la Lengua Española, 2007. p. XCVII-CXXVI.

HOWES, Marjorie. 'Goodbye Ireland I'm going to Gort': geography, scale and narrating the nation. In: ATTRIDGE, Derek; HOWES, Marjorie (Orgs.). Semicolonial Joyce. Cambridge: Cambridge University, 2000. p. 37-57.

JOYCE, James. Os mortos. In: Dublinenses. Tradução: Hamilton Trevisan. 3. ed. Rio de Janeiro: Civilização Brasileira, 1984. p. 155-195. 160 . The Dead. In: Dubliners. Hertfordshire: Wordsworth Classics, 1993. p. 127-

LOOMIS Jr, C. C. Structure and sympathy in Joyce's 'The Dead'. PMLA, v. 75, n. 1, p. 149-151, mar. 1960. Disponível em: < http://www.jstor.org/stable/460438>. Acesso em: 02/12/2008.

MÁRQUEZ, Gabriel García. Cien años de soledad. Madrid: Asociación de Academias de la Lengua Española, 2007.

MENDOZA, Plinio Apuleyo. El olor de la guayaba: conversaciones con Gabriel García Márquez. Bogotá: Norma, 2005.

MORETTI, Franco. One hundred years of solitude. In: Modern epic: the world-system from Goethe to Garcia Marquez. London/ New York: Verso, 1996. p. 233-250. 
SARAMAGO, V. O DE SEMPRE E O DE NUNCA...

MOORE-GILBERT, Bart. Postcolonial modernism. In: BRADSHAW, David; DETTMAR; KEVIN, J. H. A companion to modernist literature. Blackwell Publishing, 2006. p. 551-557.

MOURA, Jean-Marc. Pour une théorie postcoloniale francophone. In: francophones et théorie postcoloniale. Paris: PUF, 1999. p. 139-160. Littératures

NOLAN, Emer. Nationality and literature: the case of 'The Dead'. In: James Joyce and Nationalism. London: Routledge, 1995. p. 24-35.

PALERMO, Zulma. Comparatismo contrastivo y hermenéuticas pluritópicas: variaciones latinoamericanas. In: D'ANGELO, Biagio. Espacios y discursos compartidos en la literatura de América Latina: actas del $1^{\circ}$ Coloquio del Comité de Estudios Latinoameiranos de la AILC/ICLA. Lima: International Comparative Literature Association: Fondo Editorial de la Universidad Católica Sedes Sapientiae, 2003. p. 319-331.

PECORA, Vincent P. 'The Dead' and the generosity of the word. PMLA, v. 101, n. 2, p. 233245, mar. 1986. Disponível em: <http://www.jstor.org/stable/462406>. Acesso em: $02 \mathrm{dez}$. 2008.

POLAR, Cornejo. Problemas e perspectivas da crítica literária latino-americana. In: VALDÉS, Mario (Org.). O condor voa: literatura e cultura latino-americanas. Belo Horizonte: UFMG, 2000. p. $15-18$.

QUAYSON, Ato. Fecundities of the unexpected: magical realism, narrative, and history. In: MORETTI, Franco (Org.). The novel. Princeton and Oxford: Princeton University, 2006. v. 1, p. $726-756$.

RAMA, Ángel. Os processos de transculturação na narrativa latino-americana. In: AGUIAR, Flávio; VASCONCELOS, Sandra Guardini (Orgs.). Ángel Rama: literatura e cultura na América Latina. São Paulo: Edusp, 2001. p. 209-238.

RAMÍREZ, Sergio. Atajos de la verdad. In: MÁRQUEZ, Gabriel García. Cien años de soledad. Madrid: Asociación de Academias de la Lengua Española, 2007. p. 529-546.

SLEMON, Stephen. Magic realism as postcolonial discourse. In: FARIS, Wendy B.; ZAMORA, Lois Parkinson (Orgs.). Magical realism: theory, history, community. Durham: Duke University, 1995. p. 407-426.

TATE, Allen. The Dead. In: JOYCE, James. Dubliners. London: Penguin Books, 1996. p. 389394.

TITTLER, Jonathan. Gabriel García Márquez: la encarnación de la ironía. In: Ironía narrativa em la novela hispanoamericana contemporánea. Trad. Carmen Barvo. Bogotá: Banco de la República, 1990. p. 217-260.

Enviado em: 26/10/2009

Aceito em: 11/12/2009 